\title{
Evaluation of Airport System of Systems from a Human Stakeholder Perspective using a Value Operations Methodology (VOM) Assessment Framework
}

\author{
R. Curran ${ }^{1}$, F. Smulders ${ }^{2}$ and F. van der Zwan ${ }^{3}$
}

Air Transport and Operations Section, Faculty of Aerospace Engineering, Delft University of Technology

\begin{abstract}
This paper describes the development of the Airside Value Model. In the field of airport operations and airport performance measurement, there is much focus on 'economical performance'. Additionally, Key Performance Indicators to assess airside operations are used, but these sets of KPIs are very diverse and the reasons for measuring them are not always clear. Moreover, these KPIs are not used to actually drive the operations at the airport's airside. The Airside Value Model seeks to expand this limited domain by allowing airport managers to assess the Value created in their airside operations and use this information to optimize them. This Value measurement goes beyond just economical considerations, but also includes operational performance, environmental aspects et cetera. It has been shown that the Airside Value Model is able to measure these different aspects of Value and link them to operational processes. However, more work is required to enhance its effectiveness.
\end{abstract}
$\Delta V=$ delta Value
$\mathrm{C}=$ Capacity
$\mathrm{CR}=$ Consistency Ratio
${ }_{c} \alpha=$ Capacity aspect weight factor
$\mathrm{O}=$ Operations
$\mathrm{CI}=$ Consistency Index
${ }_{o} \alpha=$ Operations aspect weight factor
$\mathrm{Ec}=$ Economics
$\mathrm{RI}=$ Random Inconsistency Index
${ }_{e c} \alpha=$ Economics aspect weight factor
$\mathrm{E}=$ Environment
$e \alpha=$ Environment aspect weight factor
$\lambda=$ eigenvalue

\section{Introduction}

$\mathrm{R}$ ather than only looking at specific and isolated examples of human factors and human-machine interface, there is also a need for a more System of Systems (SoS) approach within ATM which first evaluates the value added to all human stakeholders. This should be carried out at both a at the level of systems' design (infrastructure) and also systems' process (operations) in order to the address the true impact on all human stakeholders. If some system design or process improvement is found to add value at the SoS level then the analysis deepens to the more typical human factors studies that we find becoming more prevalent in ATM, as the role of the human in the loop is elevated to its rightful position as a key actor.

However, at any level it is difficult to assess the many performance attributes that become real through operation, i.e. when technology is implemented in the provision of a service by multi-operators. Consequently, the authors have been developing a Value Operations Methodology (VOM) that provides an assessment framework for the inclusion of many stake holders at a SoS level and which facilitates the trade-off of disparate performance indicators such as efficiency, capacity, cost, environmental impact and safety. A VOM assessment tool was developed for the airport SoS case and was tested against the ACARE scenarios at a SoS level but also applied at the lower level operational process level, relative to the various stakeholders. Consequently, results will be presented for the value assessment of a number of future airport scenarios, similar to that identified by ACARE. Subsequently, the analysis framework will then be specifically applied to the environmental processes associated with noise control at a specific regional airport.

\footnotetext{
${ }^{1}$ Head, Air Transport \& Operations, Kluyverweg 1, 2629HS, AIAA Senior Member.

${ }^{2}$ Masters Graduate, Air Transport \& Operations, Kluyverweg 1, 2629HS,.

${ }^{3}$ Assistant Professor, Air Transport \& Operations, Kluyverweg 1, 2629HS, AIAA Member.
}

American Institute of Aeronautics and Astronautics 
Finally, the paper will draw conclusions regarding the value perspective of the human stakeholder in terms of various performance metrics that they prioritize. The main goal of the assessment at the SoS level is the strong potential for alternative reasoning to become apparent, indeed as emergent behaviour gives rise to an overall system behavior that may not have been anticipated or even considered by a single stakeholder how is more focused on their own immediate position. The conclusions will then be tested at a more detailed level to see if the same holds true when the assessment is carried out for a specific process; noise management. Once again, how does our assessment of the role of the human change when we view it from a more holistic view point associated with many stakeholder requirements. Noise abatement is a very pertinent case study as apart from involving ATC, the airport and the airline, we also have the perspective of the local community.

The main research conclusion will be that it is necessary to have a more inclusion assessment framework and set of value metrics in order to effectively capture the role of the human stakeholder in air transport, and that the Value Operations Methodology coupled with a Systems of Systems modelling approach can be utilized to do that. Ashford et al. (1991) or De Neufville and Odoni (2003).

\section{The Airport System of Systems Adding Value}

The airport as a System of Systems (SoS) an be conceptualized as in Figure 1 for both SoS architecture and the human stakeholders. Values are typically established relative to how the main stakeholders are influenced and benefit from the performance of the air transport system in its entirety. These values range from those driven by the airline, airport operator or air traffic controller to those of the Government or regulator, politicians, community and of course the passengers. These stakeholders may well then develop their own objectives relative to their concerns but certainly in terms of delivering a sustainable business the Airport stakeholders define certain objectives relative to the very tangible requirements of the CEO, director of strategic planning, domain planners, experts and consultants. Finally, Figure 1 has the operational primary systems and their processes which need to be controlled and optimized at the most basic level to influence value creation back up at the SoS level.

One of the most complete and thorough methodologies for thinking about stakeholders, value and tradeoffs in decisions with multiple objectives is offered by Ralph Keeney and his colleagues in an extensive series of books and papers (Keeney, (1988), (1996), Keeney and Gregory (2004), Keeney and McDaniels (1999), Keeney and Raiffa (1993), Keeney et al. (2006)). These methods, which can best summarized by the term 'Value-focused

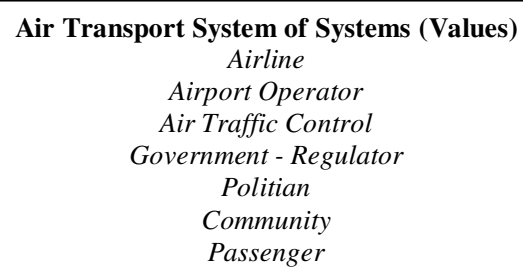

Passenger

Airport System of Systems (Objectives)

CEO

Director Strategic Planning

Domain planners

Experts

Consultants

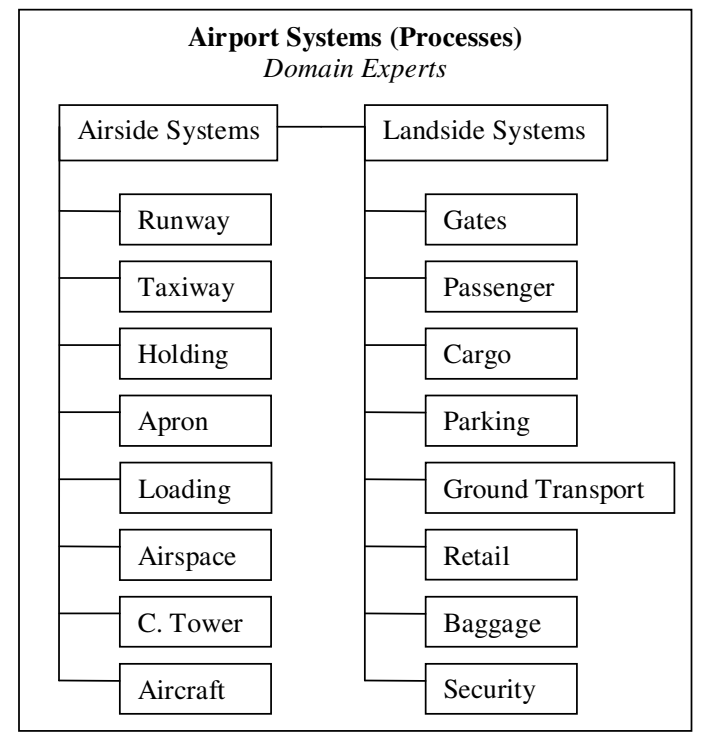

Figure 1 The Airport Systems of System Value Model 
thinking', offer the most systematic way to explicitly analyze all of the above aspects when trying to come up with the best alternative in any kind of (business) decision problem. In Value-focused thinking, the first step in a decision problem is to make the set of implicit values that are involved explicit. By thinking clearly about what is that one finds important in the decision problem, a complete list of values can be written down. This complete list of values can then be translated into a list of objectives. Whereas a Value is somewhat of a vague term, an objective clearly defines how decision makers seek to contribute to this Value.

Relative to Figure 1 and as per Keeney's value theories, the creation of value can be described by objectives that need to be fulfilled, and attributes that can be defined to measure the achievement of these objectives. Finally, the airside processes are the physical phenomena which give input to the attributes and as such create (or destroy) the Airside Value. Not only do the processes affect the score of the attributes in an individual way, they can also have influences on each other (because of operational interdependencies) and as such, may compound the score on certain attributes. The processes can of course be further detailed by splitting them up into sub-processes, which may even be broken down all the way to the level of individual activities. However, the following Section will expand on the utilization of Value Operations Methodology (VOM) from Curran et al (2009) in establishing a VOM airport model as an objective function.

\section{VOM Airport Model Development}

\section{A. Formalizing values into an objective value function}

The Airside Value Function will be constructed in a number of steps. As said before, the first step is to define for all relevant stakeholders their network of objectives. Once these are defined, a set of fundamental objectives can be derived from it, taking into account the relative importance of all stakeholders. The last step is to come to an appropriate weighing of the fundamental objectives, so that the top-level Value function can be defined. In order to get an idea of the various stakeholders' objectives, annual reports and company profiles have been studied for airports (Schipholgroup, Fraport AG and BAA), airlines (KLM-Airfrance and Lufthansa), government (Dutch government's Luchtvaartnota) and third parties (Menzies and SAS Ground). Assessing all of these parties' objectives and distilling from this long-list only the fundamental ones, it has become clear that the most important objectives in airport airside operations are actually quite close to the domains of the current Key Performance Indicators, namely Economics, Capacity, Environment, Safety and Efficiency. This leads to the proposed Fundamental Objectives decomposition as shown in Figure 2.

The obtained shortlist of fundamental objectives is also well in line with current research. For example, SESAR's 'Key Performance Areas' contain nearly exactly the same items, which in turn are aligned with ICAO's top level KPAs (Graham and Young (unknown year)). Furthermore, the goals and challenges for the 2020 air transport scenarios as defined by the Advisory Council for Aeronautics Research in Europe (ACARE) in their Strategic Research Agenda (ACARE (2004)) are also quite similar. This strengthens the trust in the fundamental objectives' validity.

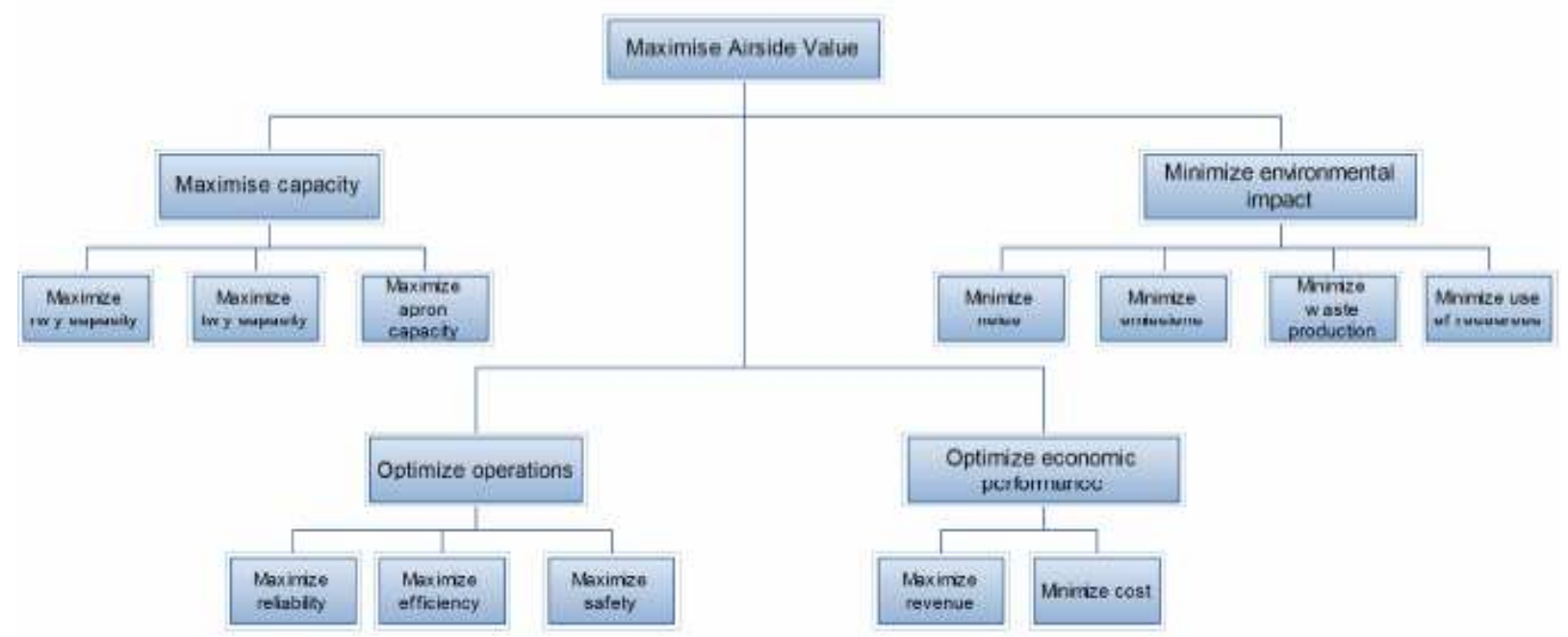

Figure 2 Mapping airport value to tangible performance objectives

American Institute of Aeronautics and Astronautics 
The shortlist of fundamental objectives to determine airside Value can be combined into the Airside Value Function. This function will take a somewhat different form from Keeney's equation, following the work of Curran et al. (2009). In the Value Operations Methodology (VOM) they propose that, instead of desiring a 'total' value number at the end of all calculation, it would be better to look for 'differential' value (delta Value). The reasoning behind this is that is it is much more logical to relate the value of one instance with another. As long as the subject under consideration (in their case: an aircraft design) has more value points than a certain reference, all is well. Obviously the reference needs to be chosen carefully in order to make the most appropriate comparison. In the previous study Curran et al (2009) compared the design options of an aircraft to the (existing) designs of their strongest competitors. The use of a differential form in the VOM, changes the 'standard' additive value function to the form:

$$
\Delta V\left(v_{1}, v_{2}, v_{3} \ldots v_{n}\right)=\sum_{j=1}^{n} \lambda_{j} \frac{v_{j 1}}{v_{j 0}}\left(x_{1}, x_{2} \ldots x_{q}\right)
$$

As can be seen, the main form of the Value function is still the same, but now uses the ratio of the value elements of instance 1 to instance 0 (the reference). Additionally, the deltaV is now a function of the separate value-elements V1 to $\mathrm{Vn}$, while these themselves are a function of the attributes X1 to Xk. The model thus essentially uses two value measurements instead of one. The second level of the value function (that of the individual elements) is modeled by summing the value contributions of the different attributes, with appropriate weights. Applying this Value-function form to the fundamental objectives, leads to the generic high-level Airside Value Function:

$$
\Delta V=\alpha_{c} \frac{C_{1}}{C_{0}}+\alpha_{o} \frac{O_{1}}{O_{0}}+\alpha_{e c} \frac{E c_{1}}{E c_{0}}+\alpha_{e} \frac{E_{1}}{E_{0}}
$$

In this Airside Value Function, the four different aspects of Capacity (C), Operations (O), Economics (Ec) and environment (E) are weighed by the respective $\alpha$ 's and added together. Since each part of the function is a ratio instead of an absolute number (and thus dimensionless), it is possible to add them into the final Value figure without running into mathematical problems. The four weighing factors will be determined by creating a number of scenarios or profiles. For example if the focus is on being environmentally friendly, the E component of the function should be given a lot of weight, whereas a cost-effective airport will create most Value in the economics of its operations. In the same Strategic Research Agenda as mentioned earlier, ACARE (2004) has described 5 possible airport types in 2020, which it has called High Level Target Concepts (HLTCs). These concepts reflect the possible ways in which future airports are expected to specialize themselves, and the corresponding importance that is given to aspects such as cost, capacity, environment etc. ACARE has related all scenarios to so-called 'Challenges'. These challenges have many similarities with the airside fundamental objectives. As such, the scenarios can be (roughly) translated into the different possible Value function weighing factors as shown in Table 1 below.

Table 1: Possible Value function weights for different airport scenarios

\begin{tabular}{|l|l|l|l|l|l|}
\hline & & \multicolumn{4}{|l|}{ Fundamental objective weighing factors } \\
\hline Airport scenario & & Capacity [C] & Operations [O] & Economics [Ec] & Environment [E] \\
\hline Customer-oriented airport & & 0.20 & 0.50 & 0.15 & 0.15 \\
\hline Time-efficient airport & & 0.20 & 0.60 & 0.10 & 0.10 \\
\hline Cost-efficient airport & 0.10 & 0.20 & 0.60 & 0.10 \\
\hline Ultra-green airport & 0.10 & 0.10 & 0.10 & 0.70 \\
\hline Ultra-secure airport & 0.10 & 0.40 & 0.40 & 0.10 \\
\hline
\end{tabular}

The generic Value function may be detailed further by splitting the four high level aspects of Capacity, Economics, Operations and Environment down over their respective sub-objectives, as already seen in Figure 3. Looking at equation 3 and using the aforementioned sub-objectives, yielded the high level Value function: 


$$
\begin{aligned}
\Delta V & =\alpha_{c}\left[\alpha_{c 1} \frac{\text { Rwy_cap }_{1}}{\text { Rwy_cap }_{0}}+\alpha_{c 2} \frac{\text { Twy_cap }_{1}}{\text { Twy_cap }_{0}}+\alpha_{c 3} \frac{\text { Apr_cap }_{1}}{\text { Apr_cap }_{0}}\right] \\
& +\alpha_{o}\left[\alpha_{o 1} \frac{\text { Reliab }_{1}}{\text { Reliab }_{0}}+\alpha_{o 2} \frac{\text { Efficiency }_{1}}{\text { Efficiency }_{0}}+\alpha_{o 3} \frac{\text { Safety }_{1}}{\text { Safety }_{0}}\right] \\
& +\alpha_{e c}\left[\alpha_{e c 1} \frac{\text { Revenue }_{1}}{\text { Revenue }_{0}}+\alpha_{e c 2} \frac{\text { Cost }_{1}}{\text { Cost }_{0}}\right] \\
& +\alpha_{e}\left[\alpha_{e 1} \frac{\text { Noise }_{1}}{\text { Noise }_{0}}+\alpha_{e 2} \frac{\text { Emissions }_{1}}{\text { Emissions }_{0}}+\alpha_{e 3} \frac{\text { Waste }_{1}}{\text { Waste }_{0}}+\alpha_{e 4} \frac{\text { Resources }_{1}}{\text { Resources }_{0}}\right]
\end{aligned}
$$

\section{B. Allocating measurable attributes to the value objectives}

As explained in the outline of this chapter, the scope of the project makes it impractical to try and set up specific attributes for each individual process; therefore a top-level group will be constructed that directly fits with the fundamental objectives. With the current knowledge of the airside processes, the selected fundamental objectives, and using the current literature's most known Key Performance Indicators as a guide, the set of attributes in Table 2 is proposed. From the table it can be seen that (where possible) the attributes will be measured as a 'per movement' amount. This again makes it more easy to decompose the processes down to an activity level: 1 aircraft coming and

\begin{tabular}{|c|c|c|c|}
\hline Fundamental objective & Detailed objectives & Attributes & Unit \\
\hline \multirow[t]{3}{*}{ Maximize capacity } & Maximize runway capacity & Peak day hourly runway movements & {$[-/ h r]$} \\
\hline & Maximize taxiway capacity & Peak day hourly taxiway movements & {$[-/ h r]$} \\
\hline & Maximize apron capacity & Peak day hourly tumarounds & {$[-/ \mathrm{hr}]$} \\
\hline \multirow[t]{4}{*}{ Optimize operations } & Maximize reliability & Amount of delay per movement & [min/movement] \\
\hline & Maximize efficiency & Average process completion time & [min] \\
\hline & Maximize safety & Number of accidents per movement & [-/movement] \\
\hline & & Number incidents per movement & {$[-/$ movement $]$} \\
\hline \multirow[t]{3}{*}{ Optimize economic performance } & Maximize revenues & Aeronautical revenues per WLU & {$[€ N L U]$} \\
\hline & Minimize cost & Operating cost per WLU & [@NLU] \\
\hline & & Labour cost per WLU & [ENLU] \\
\hline \multirow[t]{6}{*}{ Minimize environmental impact } & Minimize noise & Average noise during day, evening and night (Lden) & {$[\mathrm{dBA}]$} \\
\hline & Minimize emissions & Amount of $\mathrm{CO} 2$ per movement & [kg/movement] \\
\hline & & Amount of NOx per movement & [kg/movement] \\
\hline & Minimize waste production & Waste water per movement & [L/movement] \\
\hline & & Solid waste per movement & [kg/movement] \\
\hline & Minimize use of resources & Water consumption per movement & [L/movement] \\
\hline
\end{tabular}
going at the airside. Also, it allows one to compare airports regardless of size, which will make the model more widely applicable.

Table 2: Airside Value Function attributes set

\section{Allocating degree of influence to the attributes using analytical hierarchy process}

In order to determine the weights of the different attributes, the same technique as used in the Analytical Hierarchy Process will be employed. The AHP is well suited for this task of weighing, as it allows one to rate relatively abstract items (which may sometimes be difficult to compare) in a systematic and proper mathematic fashion which also provides a consistency check. However, as the AHP is already a tradeoff process in itself, it will only be used partially in the Airside Value model. More precisely, only the first part of pair-wise comparison will be done, as this allows us to determine the relative importance of each attribute. The second part of the AHP, which consists of determining one figure of merit for an alternative will not be used, as this will result into only one final objective being selected as 'the best'. Furthermore, the various attributes will be compared only within their own domain. That is to say, the capacity attributes will only be compared to each other, as will the environmental ones et cetera. This will be done for two reasons. First, it is practically impossible to compare more than 10 attributes to each other, not only because this would require one to fill out a 10 x 10 matrix (or bigger) of comparisons, but also because the Random Consistency Index (RI) has only been provided for up to $n=10$. Secondly, there is no sense in asking someone how much more important the hourly runway capacity is than the yearly amount of $\mathrm{CO}_{2}$ emissions. But on a group level, this comparison does make sense as different airport situations, its operations and the stakeholder in 
question can produce very different, but defendable weights on for example the importance of noise versus pollution, or reliability versus efficiency.

In order to most adequately integrate the AHP with the Airside Value model, it is first important to recognize that there are two ways in which the model can actually be applied to an airport. The first way of application, which will be called the ' 1 st tier approach', involves using the model on a high level to compare the overall airport's airside operations with those of one or more competitors. At this level, the person using the model is mostly interested to get a broad idea of the airport's performance and airside Value creation. As such, the weights given to the different attributes should reflect this person's (and airport's) views on Value, and which aspects are more or less important. The 1 st tier approach is thus a more subjective one, allowing airport managers (or other stakeholders) to evaluate the airport from their own viewpoint.

The second application of the model, the '2nd tier approach', occurs when one is interested in the detailed relationship between specific processes and airside Value creation. In such a case, the focus is on a specific airport and its own characteristic processes, and how a certain change in these processes may affect the Value. This would be when there is a proposal to start an improvement project, and management wishes to assess if this project's outcomes actually help increase Value as it is perceived at this specific airport. Then, the attribute weights should be assigned according to how they are affected by the process changes: if a certain process is expected to change an attribute strongly, this attribute should be given more weight, so that the change in the process results in a noticeable change in Value. For example, if a certain change would be expected to result in a substantially higher number of incidents, a high weight on this attribute will immediately lower the Value, thus showing the negative impact of the change. The 2-tier approach thus requires two methods by which the AHP matrices are filled in: a more subjective way in case of the high level, 1 st tier approach, versus a more formalized one in the process-driven, 2nd tier approach.

\section{Systems of Systems Design Validation: General Airport Performance Rating}

Before the first-tier analysis could be carried out, it was necessary to establish the low-level weight factors to be used in the Value function. For the different weight vectors, BasePort's operational focus (as identified by the operations manager) was used. It was envisioned that this airport is run in very standard fashion: there is much focus on runway and apron capacity, as these are relatively most congested. In operations, there is some interest in efficiency and reliability, but the main aim is mostly to keep it safe. Also, since the aeronautical revenues are mostly unchanging, the focus in the economics part lies mostly on keeping operational cost under control. Labor cost is also important in this sense, but as worker's wages are most likely very inflexible due to union agreements, there is less leeway here. Finally, the environmental focus is also very traditional: the impact of noise and $\mathrm{CO}_{2}$ are most pressing to the manager, followed only by that of $\mathrm{NO}_{\mathrm{x}}$. The use and emission of water and waste are considered 'good enough', and therefore are not much of a concern. This focus was used in comparing the different attributes in the AHP, which has led to the following set of attribute weights:

Table 3: Resulting weight factors for BasePort in scenario analysis

\begin{tabular}{|c|c|c|c|c|c|c|}
\hline Matrix & Largest real eigenvalue & Consistency Ratio & \multicolumn{4}{|c|}{ Normalized eigenvector } \\
\hline Capacity & 3,00 & $0,0 \%$ & \begin{tabular}{l|l|} 
& 0,44
\end{tabular} & 0,22 & 0,33 & \\
\hline Operations & 4,00 & $0,0 \%$ & 0,17 & 0,17 & 0,33 & 0,33 \\
\hline Economics & 3,01 & $0,5 \%$ & 0,10 & 0,47 & 0,43 & \\
\hline Environment & 6.25 & $3,8 \%$ & 0,39 & 0,30 & 0,14 & \begin{tabular}{|l|l|l|}
0,05 & 0,06 & 0,06 \\
\end{tabular} \\
\hline
\end{tabular}


Table 4: Scenario airport data

\begin{tabular}{|c|c|c|c|c|c|}
\hline Objective group & Attribute & AdvancePort & BusyPort & CashPort & DreamPort \\
\hline \multirow{3}{*}{ Capacity } & Runway movements [/hr] & 95 & 120 & 90 & 85 \\
\hline & Taxiway movements [/hr] & 105 & 130 & 110 & 100 \\
\hline & Apron movements [/hr] & 105 & 130 & 110 & 100 \\
\hline \multirow{4}{*}{ Operations } & Delay $[\mathrm{min} / \mathrm{move}]$ & 2 & 8 & 5 & 7 \\
\hline & Avg. Process time [min/move] & 6 & 12 & 12 & 15 \\
\hline & Incidents [/move] & 0,0003 & 0,0006 & 0,0004 & 0,0006 \\
\hline & Accidents [/move] & 0,000003 & 0,000005 & 0,000004 & 0,000006 \\
\hline \multirow{3}{*}{ Economics } & Aeronautical Revenues [ $€ /$ move] & 1500 & 1400 & 1800 & 1300 \\
\hline & Operational cost [€/move] & 3000 & 2600 & 2000 & 2300 \\
\hline & Labor cost [€/move] & 1450 & 1250 & 850 & 1300 \\
\hline \multirow{6}{*}{ Environment } & Noise [dBA] (Lden) & 72 & 80 & 75 & 65 \\
\hline & $\mathrm{CO} 2[\mathrm{~kg} / \mathrm{move}]$ & 120 & 175 & 150 & 100 \\
\hline & Nox $[\mathrm{kg} /$ move] & 3 & 7 & 5 & \\
\hline & Wastewater [L/move] & 375 & 420 & 375 & 300 \\
\hline & Solid waste $[\mathrm{kg} / \mathrm{move}]$ & 50 & 60 & 50 & 60 \\
\hline & Water [L/move] & 200 & 200 & 200 & 150 \\
\hline
\end{tabular}

Thus, having obtained the low-level weight factors and knowing the operational data of four (imaginary but distinctly different) competitor airports, the Value number can be calculated. Using Equation 3 and making BasePort the reference (airport 0), the Value score of the competitors can be calculated for the five possible profiles.

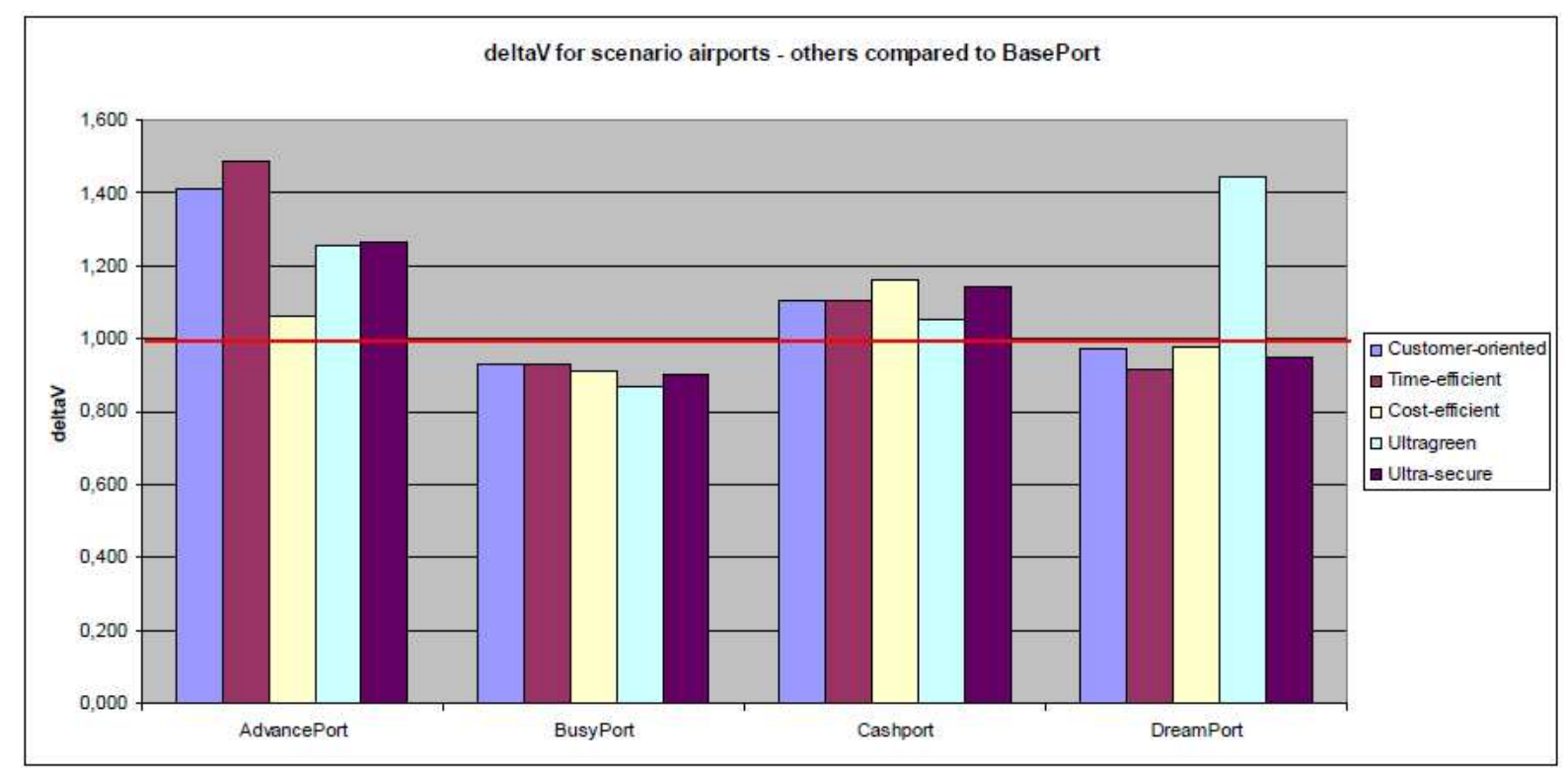

Figure 3 DeltaV score for scenario airports relative to BasePort

As can be seen Figure 3, three out of the four competitor airports are outperforming BasePort on at least one profile type. For example, AdvancePort is very good as a Customer-oriented and Time-efficient airport, which can be explained by its very-well organized operations. Especially the high score in safety contributes greatly to the deltaV in this respect, as it is deemed most important in this analysis. Similarly, it scores well as a Ultragreen airport and a safe airport. Finally, even the relatively higher costs of AdvancePort are offset by the gains in performance in other areas, making it also better as a Cost-effective airport than BasePort. Similarly, it is clear that BasePort is better than BusyPort in any type of profile, as the latter's higher capacity score is offset by its relatively poor performance in all other areas. CashPort on the other hand is again doing better than BasePort in all configurations, although not much. While there is no difference in capacity and most environmental impacts, the better use of money and resources and higher safety create a better deltaV. It is no surprise that this airport performs best as a Cost-effective one, because in that case most merit is given to the current cost-cutting measures. Finally, DreamPort is only better in a Ultragreen role. Only then are this airport's poor performance on cost, operations and economics offset by its high 
scoring on environmental-friendliness. From the analysis above, BasePort's manager has learned that measures will be necessary to improve airside operations. It may not be possible to immediately outdo AdvancePort on all areas, but action is needed to ensure the airport does not stay behind like BusyPort.

\section{Systems of Systems Process Validation: Specific Acoustic Noise Optimisation}

The Airside Value Model was applied to a case study involving Rotterdam airport. Rotterdam Airport is required by law to operate within a certain noise zone: the aircraft landing at, or taking off from Rotterdam Airport can only produce a certain amount of noise, over certain areas around the airport, in a year. This means the airport is restricted in the amount of traffic it can handle due to noise capacity limitation. Actually, the strongest limiting factor in Rotterdam Airport's capacity is the effect of night flights on the noise contour. According to the Kosten noise calculation method, night flights are penalized by a factor of 10 (!) on their noise production, because at this time it is deemed that aircraft noise is the most annoying to residents. Since the total amount of noise allowed over one year is fixed, this means that 1 aircraft flying at night is equal to 10 aircraft arriving during the daytime. The night aircraft thus uses up the 'noise quotum' 10 times as fast, and this severely limits the overall annual airport capacity. In order to combat this, heavy night surcharges (of up to more than $150 \%$ of the normal landing tariff) have been put in place, but this is not enough to cover the losses due to the effective reduction in overall annual capacity. In fact, the situation is made worse due to the high number of business and training flights at Rotterdam Airport. Since especially the business flights often have to arrive at night, but have very low load factors, the actual revenues that are obtained (both on a per aircraft level as well as per passenger) are quite low, whereas the loss of overall capacity (due to the night noise penalties) is very high (Mohamed et al. (2009)). Thus, ideally, Rotterdam Airport should strive to only accommodate daytime flights, focusing only on commercial flights. This would then cost less in terms of noise, but bring in most revenues per passenger. Based on the Rotterdam Airport situation as outlined above, it has been decided to test the scenario of what would happen if no night flights were conducted anymore, and all aircraft would be commercial, while the existing noise limits are kept fixed. This change will occur using the year 2009 as the current state and 2010 as the future state.

It is expected these operational changes will lead to a higher annual capacity, with corresponding higher revenues, but also lead to more environmental load especially in terms of $\mathrm{CO}_{2}$ emissions. The Airside Value Model is in this case the ideal tool to assess if the gains in terms of capacity and income are higher than the losses due to environmental cost. As this kind of airport assessment is one of a high, strategic level not concerning 'per-flight' processes, it is thus a 1 st tier analysis. In applying the Airside Value Model this case it was thus necessary to gather data for all the attributes, and to estimate what these numbers would become in the future state (2010). The effective capacity with the same noise contour using only B737 aircraft was analyzed with the Integrated Noise Model (INM), but the other attribute numbers turned out to be quite difficult to find. Actually, only the new revenues and $\mathrm{CO}_{2}$ emissions could be estimated simply with the works of Mohamed et al. (2009) and Liem (2010); the others had to be estimated. At this time the usefulness of the deltaV was seen the best: because the final Value number is calculated based on the ratio of state 0 (current) to state 1 (future) it is not necessary to know the actual numbers: the expected percentile increase is enough. As such, all attribute ratios could be found even in the absence of real data. Thus the following set of attributes and attribute ratios is established: 
Table 5: Attributes for Rotterdam airport case

\begin{tabular}{|c|c|c|}
\hline Attribute & $2010(\mathrm{~B} 737)$ & Attribute ratio (2010/2009) \\
\hline Total aircraft movements [/yr] & $52905 \quad 23360$ & $\begin{array}{r}0,442 \\
\end{array}$ \\
\hline $\begin{array}{l}\text { Delay [min/move] } \\
\text { Avg. Process time [min/move] } \\
\text { Incidents [/move] } \\
\text { Accidents [/move] }\end{array}$ & Assumed similar between year $0-1$ & $\begin{array}{l}1,000 \\
1,000 \\
1,000 \\
1,000\end{array}$ \\
\hline Aeronautical Revenues [€/yr] & $€ \quad 15.355 .262,54 \quad € \quad 35.416 .680,00$ & 2,306 \\
\hline $\begin{array}{l}\text { Operational cost [€/yr] } \\
\text { Labor cost [€/yr] }\end{array}$ & $\begin{array}{l}\text { Assumed to increase between } 10 \% \text { (lowest) } \\
\text { and } 130 \% \text { (=revenues) }\end{array}$ & $\begin{array}{l}0,909 \\
0,909\end{array}$ \\
\hline Noise [dBA] (Lden) & Assumed similar between year $0-1$ & 1,000 \\
\hline $\mathrm{CO} 2[\mathrm{~kg} / \mathrm{yr}]$ & $6,70 \mathrm{E}+06 \quad 1,26 \mathrm{E}+07$ & 0,532 \\
\hline $\begin{array}{l}\text { Nox [kg/yr] } \\
\text { Wastewater [L/yr] } \\
\text { Solid waste [kg/yr] } \\
\text { Water [L/yr] }\end{array}$ & $\begin{array}{l}\text { Assumed to increase proportional with } \\
\qquad \mathrm{CO} 2\end{array}$ & $\begin{array}{l}0,532 \\
0,532 \\
0,532 \\
0,532\end{array}$ \\
\hline
\end{tabular}

With the establishment of all attributes, the only thing left to do was the selection of weighting factors with the $1_{\text {st }}$ tier AHP. Although the ideal situation would be to let a manager from Rotterdam Airport fill in this matrix, it is only possible to establish these weights as an educated guess. The AHP matrices are filled in based on the knowledge about Rotterdam airport's operations and focus obtained from the work of Mohamed et al. (2009a) and through discussion with experts at the TU Delft. With the attribute ratios and weight factors determined in this way, the deltaV for the Rotterdam airport case can now be calculated for the 5 different ACARE scenarios. The results are shown in Figure 4.

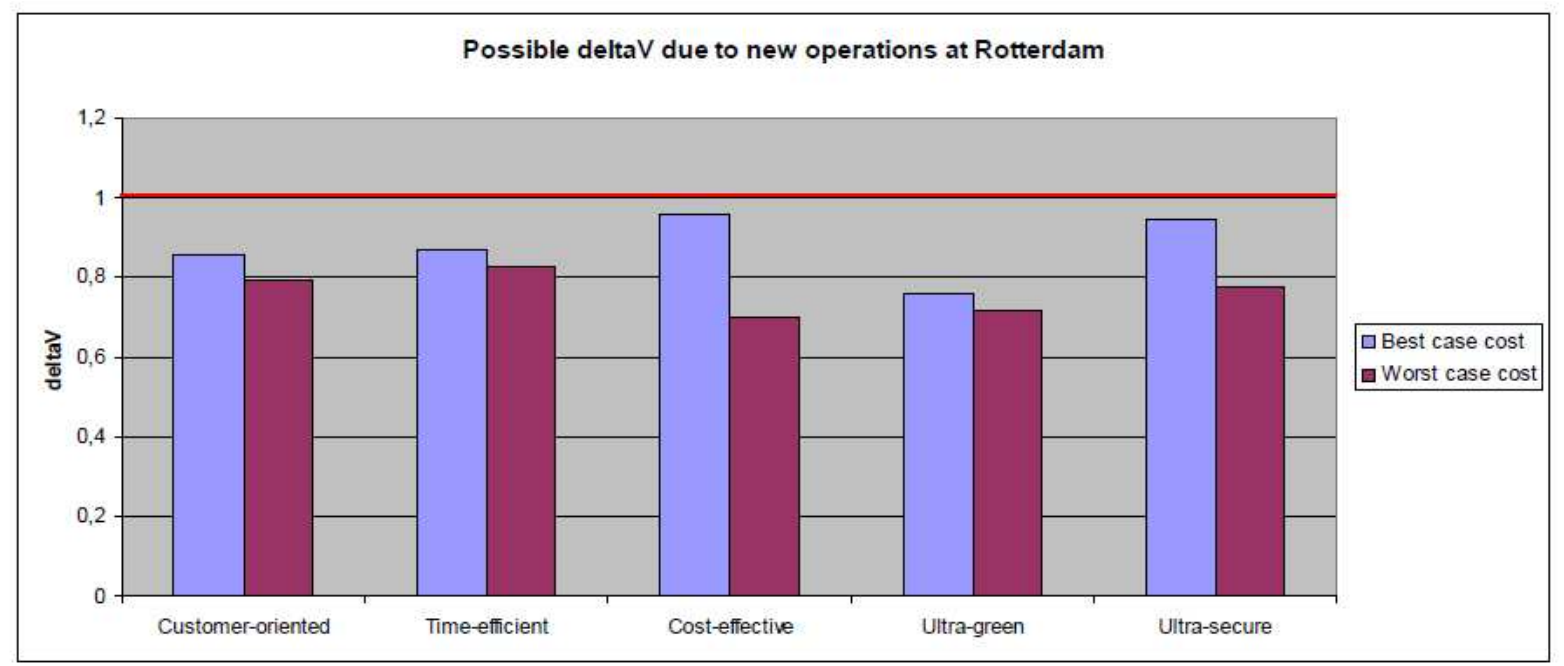

Figure 4 DeltaV due to new operations at Rotterdam

These deltaV results are very interesting. As it turns out, the switch to day-only, B737 only flights operations does not result in higher Value creation at the airside. This is actually contrary to what was expected beforehand. However, taking a look at the inputted attributes and weight factors explains much. For starters, it was expected that the annual capacity would increase; this however has not happened. In fact, the total capacity has decreased sharply, which is mainly due to the fact that B737 aircraft still produce a lot of noise. Although there are no more penalties due to night flights, the possible gain in B737 flights is nowhere near enough to surpass the 2009 amount of 52000 flights. This in turn shows that the training flights are actually very important to Rotterdam airport in terms of capacity, as they can be carried out quickly and in large numbers, and due to the small aircraft size do not contribute much to the noise limit. However, it should be mentioned here that, in terms of B737 capacity only, there has been an increase as the 2009 amount of this specific aircraft was only about 6400 flights. But since we are counting total airport capacity, this does not count. 
Secondly, the overall economic performance has also not increased substantially. Although clearly the aeronautical revenues are expected to double due to the substantially higher number of B737 aircraft being serviced, this is offset by the expected increase in cost due. Even in the best case scenario there are 2 out of 3 cost attributes that have decreased performance. Even worse, it is exactly these cost attributes which are given the highest weight, thus strengthening their impact. This is even more severe for the worst case scenario: here the doubling in revenues is effectively negated by the expected doubling of associated costs, which again have a substantially higher weight.

Finally, the amount of emissions has increased substantially. Although not all aircraft types were counted for 2009, it is clear that the switch to only B737 effectively doubles the amount of $\mathrm{CO}_{2}$. Consequently, it is estimated that all other environmental burdens will also increase nearly twofold. This is the final factor that results in a loss instead of a gain in Value: since all environmental attributes (except noise) are detracting from Value, they too detract all gains that have been brought in the form of (only) higher aeronautical revenues. These results illustrate how the Airside Value Model is able to give a broader and better insight in the net effects of operational changes, beyond purely economic ones. That is to say, at first sight this proposed scenario for Rotterdam airport indeed seems a good one: noise penalties of the night flights are removed, freeing up capacity, and only high-yielding aircraft operations are allowed. If managers would make the decision to pursue this scenario (as could likely be the case, especially in more privately-owned airports other than Rotterdam), they would neglect all negative impacts this scenario has but which can not so easily be expressed in money. The first of these impacts is indeed the actual loss in capacity. Although the B737 operational capacity does increase, the total airport 'throughput' drops sharply. This is already a loss in Value in itself, given the fundamental airport objective to maximise available capacity. But even more: all business and trainer aircraft that are now banned need to move elsewhere. This fact actually constitutes another drop in Value: customer satisfaction will probably drop now that pilots can not easily land at Rotterdam anymore. This kind of Value is not even taken into account in the model yet. But the most important impact that the Value model captures is in fact the Environmental aspect. Although the noise amount, which in this case is the most important environmental burden, stays the same, much more impact is created in the form of emissions $\left(\mathrm{CO}_{2}\right.$ and $\left.\mathrm{NOx}\right)$, waste production and use of resources. These types of equally important impacts would not have been easily foreseen in a purely economic analysis, but the Airside Value model does capture them. As such, this analysis shows that it is very important to take account of more than purely economic considerations when conducting changes in airport airside operations.

\section{Conclusion}

This paper described the development of an Airside Value Model that aimed to incorporate a wide range of KPIs and to expand this limited assessment domain by allowing airport managers to assess the Value created in their airside operations and use this information to optimize them. This Value measurement goes beyond just economical considerations, but also includes operational performance, environmental aspects et cetera. It has been shown that the Airside Value Model is able to measure these different aspects of Value and link them to operational processes. In general, the values of all human stakeholders was shown to be able to be incorporated in terms of objectives, relative to how the user implements the tool, and those objectives linked to the process that cause them, all within the SoS framework. This is a significant capability in assessing the highlevel performance of an airport systems of systems in terms of the real process that actually leverage the value and offer the air transportation and the associated value creation.

\section{Acknowledgments}

The work present was carried out as part of the MSc project of Frank Smulders, and the authors would also like to thank Rotterdam Airport for the collaboration on the noise case study.

\section{References}

Advisory Council for Aeronautics Research in Europe (ACARE), Strategic Research Agenda 2, Volume 1, 2004 Ashford, N., Martin Stanton, H.P. and Moore, C.A., Airport operations, Pitman, London, 1991

Beelaerts van Blokland, W.W.A. and Santema, S.C., Value chain innovation and the influence of co-innovation, Faculty of Aerospace Engineering, Delft University of Technology, 2006

Beelaerts van Blokland, W.W.A., Fiksinksi, M.A., Amoa, S.O.B. and Santema, S.C., Lean Value Creation Metrics for networked organisations, Faculty of Aerospace Engineering, Delft University of Technology, 2008

Beelaerts van Blokland, W.W.A., Santema, S.C., Chettle, R.Q., Smulders, F., Renon, J. and Xiong, Y., Lean Value chain

- Boeing 787 versus Airbus A380, Faculty of Aerospace Engineering, Delft University of Technology, 2009

Curran, R., Abu-Kias, T., Repco, M.J.F., Sprengers, Y.L.J., van der Zwet., P.N.C.S and Beelaerts, W., A Value 
Operations Methodology for Value Driven Design: Medium Range Passenger Airliner Validation, Air Transport and Operations department, Faculty of Aerospace Engineering, Delft, 2009

Collopy, P.D., Aerospace System Value models - A survey and observations, AIAA Space 2009 Conference and Exposition, Pasadena, California, 2009

De Neufville, R. and Odoni, A.R., Airport systems: planning, design, and management, McGraw-Hill, 2003

Graham, R.V. and Young, D., Preparing an initial assessment of the SESAR Concept of Operations "EP3: Single

European Sky Implementation Support through Validation”, Eurocontrol Experimental Centre, France, Unknown year

Hommes, B., The evaluation of business process modelling techniques, Delft University of Technology, 2004

Keeney, R.L., Building models of values, European Journal of Operational Research 37, 1988

Keeney, R.L., Value-focused thinking: A path to creative decision making, Harvard University Press, 1992

Keeney, R.L., Value-focused thinking: Identifying decision opportunities and creating alternatives, European Journal of Operational Research 92, 1996

Keeney, R.L. and Gregory, R.S., Selecting attributes to measure the achievements of objectives, Operations research, 2004

Keeney, R.L. and McDaniels, T.L., Identifying and structuring Values to guide the integrated resource planning at BC

Gas, Operations research 47, No. 5, 1999

Keeney, R.L. and Raiffa, H., Decisions with multiple objectives - preferences and value tradeoffs, Cambridge University

Press, 1993

Keeney, R.L., Edwards, W., Miles, R.F. and von Winterfeldt, D. (Eds.), Developing objectives and attributes, Advances

in decision analysis, Cambridge University Press, pp. 104-128, 2006

Liem, S., Sustainable strategy with ECO2, Delft University of Technology, 2009

Press, Baltimore, 2001

Ministerie van Verkeer en Waterstaat en het ministerie van Volkshuisvesting, Ruimtelijke Ordening en Milieubeheer,

Luchtvaartnota - Concurrerende en duurzame luchtvaart voor een sterke economie, The Hague, 2009

Mohamed, W.M.W., Curran, R., Van der Zwan, F. and Van der Kleij, S., Evaluating the Impact of Noise Constraints on

Regional Airport Capacity and Economics: The case of Rotterdam Airport, Delft University of Technology, 2009

Mohamed, W.M.W., Curran, R., Van der Zwan, F. and Roling, P., Modelling the Effect of Night Time Penalties on

Commercial and Business Flights for Regional Airport Noise and Economics: Rotterdam Airport Case Study, Delft

University of Technology, 2009

Oei, S., Strategic management in interorganizationally related processes in aviation - building for the future of Schiphol Mainport, Delft University of Technology, 2007

Parker,D., The performance of BAA before and after privatization, Journal of Transport Economics and Policy 33, 133145,1999

\section{Corporate reports and industry statistics}

BAA Corporate Responsibility Report, 2008, published on http://www.baa.com/assets/Internet/BAA/Airports/Downloads/Static/files/BAA_Corp_Responsibility_2008.pdf

ICAO engine emissions databank, published by CAA on http://www.caa.co.uk/default.aspx?catid=702, 2007

Fraport AG Annual report, 2008 (a), published on

http://www.fraport.com/cms/investor_relations/dokbin/338/338666.annual_report_2008.pdf

Fraport AG Sustainability report, 2008 (b), published on

http://www.fraport.com/cms/sustainability/dokbin/361/361310.sustainability_report_2008.pdf

Fraport AG environment web page, http://www.fraport.com/cms/environment/rubrik/2/2868.water.htm, accessed 6-5-

2010

Halim, S., Emission data of a small regional airport, Delft University of Technology, 2010

Heathrow Flight evaluation report, 2007, published on

http://www.baa.com/assets/Internet/Heathrow_noise/Assets/Downloads/Statics/LHR_FEU_2007pdf.pdf

Heathrow annual report, 2008 (a), published on

http://www.baa.com/assets/Internet/Heathrow/Heathrow/downloads/Static/files/Heathrow_31Dec08_/Signed_Accounts0001 .pdf

Heathrow corporate responsibility report, 2008 (b), published on

http://www.baa.com/assets/Internet/BAA/Airports/Downloads/Static/files/BAA_Corp_Responsibility_2008.pdf

Heathrow environmental noise directive, 2009, published on

http://www.baa.com/assets/Internet/Heathrow/Heathrow/downloads/Static/files/LHR_NAP.pdf

KLM-AirFrance annual report, 2009, published on http://www.airfranceklm-finance.com/financial-publications.html

Lufthansa annual report, 2008, published on http://investor-relations.lufthansa.com/fileadmin/downloads/en/financialreports/ annual-reports/LH-AR-2008-e.pdf

John Menzies plc annual report, 2006, published on

http://www.johnmenziesplc.com/assets/pdf/annual/reports/annual_report_2006.pdf

SAS Ground Services, Standard Ground Handling agreement, IATA/SGHA, 2004

SchipholGroup Annual report, 2008, published on 
https://www.schiphol.nl/SchipholGroup/InvestorRelations/FinancialInformation/AnnualReports.htm

SchipholGroup stakeholders, published on

http://www.schiphol.nl/SchipholGroup1/CorporateResponsibility/OnzeStakeholders.htm, accessed 05-01-2010 